\title{
Dihydroartemisinin treatment exhibits antitumor effects in glioma cells through induction of apoptosis
}

\author{
CHUN-HUA XU*, YUE LIU*, LI-MIN XIAO, CHANG-GUI GUO, \\ SU-YUE ZHENG, ER-MING ZENG and DONG-HAI LI
}

Department of Neurosurgery, The First Affiliated Hospital of Nanchang University, Nanchang, Jiangxi 330006, P.R. China

Received December 17, 2016; Accepted August 8, 2017

DOI: $10.3892 / \mathrm{mmr} .2017 .7832$

\begin{abstract}
The present study aimed to investigate the effect of dihydroartemisinin on the proliferation of chemotherapy-resistant $\mathrm{C} 6$ rat glioma cells. The results revealed that incubation of C6 glioma cells with a range of dihydroartemisinin concentrations for $48 \mathrm{~h}$ led to a significant $(\mathrm{P}<0.02)$ reduction in the cell number. There was a -0.8 -fold reduction in the cell count following treatment with $20 \mu \mathrm{M}$ dihydroartemisinin when compared with the control cultures. Analysis of DNA synthesis using bromodeoxyuridine (BrdU) staining demonstrated a reduction in the BrdU-labeling index (LI) following treatment with $20 \mu \mathrm{M}$ dihydroartemisinin. There was a 6-fold reduction in the BrdU-LI compared with the control cultures. Incubation of the C6 glioma cells with dihydroartemisinin led to a concentration dependent reduction in the level of cyclic adenosine 3',5'-monophosphate following $48 \mathrm{~h}$. The percentage of apoptotic cells in the cultures incubated with $20 \mu \mathrm{M}$ dihydroartemisinin was $54.78 \%$ compared with $2.57 \%$ in the control cultures. Incubation of the C6 glioma cells with dihydroartemisinin for $48 \mathrm{~h}$ led to a reduction in the percentage of cells in $\mathrm{G} 2 / \mathrm{M}$ phase with an increase in G0/G1 phase. The control cells exhibited spindle-shaped morphology and were actively undergoing mitosis following $48 \mathrm{~h}$ of culture. The morphological characteristics of the cells treated with dihydroartemisinin were demonstrated to be round with small surface projections. Therefore, treatment of glioma cells with dihydroartemisinin exhibited an antitumor effect by the induction of apoptosis. Therefore, dihydroartemisinin should be evaluated further in the animal models for the treatment of glioma.
\end{abstract}

Correspondence to: Dr Dong-Hai Li, Department of Neurosurgery, The First Affiliated Hospital of Nanchang University, 17 Yongwai Main Street, Nanchang, Jiangxi 330006, P.R. China

E-mail: lidonghai178@hotmail.com

*Contributed equally

Key words: chemotherapy, DNA synthesis, mitosis, antitumor

\section{Introduction}

Malignant glioma is a primary brain tumor that frequently results in a high rate of morbidity and mortality (1). Gliomas do not metastasize but infiltrate locally, invading into adjacent tissues and exhibit a poor prognosis (2). Currently, glioma treatment involves a combination of radiotherapy, chemotherapy and surgical resection (3). However, the results of treatment are not satisfactory and the development of novel and efficient therapeutic strategies is required. Evaluation of natural products has led to the identification of a number of compounds that exhibit inhibitory effects on the growth of glioma cells. These molecules are currently in clinical trials for the treatment of glioma (3-5).

Artemisinin is isolated from the herbaceous plant, Artemisia annua in China. Artemisinin was used in China for the treatment of malaria and has exhibited promising results $(6,7)$. Chemical modification of artemisinin led to the development of certain analogs, including dihydroartemisinin, which exhibited anti-malarial activity comparable to or improved compared with artemisinin (6). In vitro studies have revealed that derivatives of artemisinin possess potential as inhibitors of proliferation in malignant tumors (8-11). The anti-proliferative effect of artemisinin was demonstrated to be greater in breast and ovarian cancer compared with lung cancer. The advantage of using dihydroartemisinin as an antitumor agent is it is non-toxic to normal cells $(11,12)$. Therefore, dihydroartemisinin can be used for the treatment of glioma due to its anti-proliferative action. A glioma cell line that is resistant to chemotherapy and commonly used to study gliomas is C6 rat cells $(13,14)$. The present study aimed to investigate the effect of dihydroartemisinin on the proliferation of C6 glioma cells. Dihydroartemisinin treatment exhibited an anti-proliferative effect on the $\mathrm{C} 6$ glioma cell growth.

\section{Materials and methods}

Cell line and culture. The C6 rat glioma cell line was purchased from the Cell Bank of the Type Culture Collection of the Chinese Academy of Sciences (Shanghai, China). The cells were cultured in RPMI-1640 medium (Gibco; Thermo Fisher Scientific, Inc., Waltham, MA, USA), containing 10\% fetal bovine serum (Gibco; Thermo Fisher Scientific, Inc.) and antibiotics, penicillin $(100 \mathrm{U} / \mathrm{ml}) / \mathrm{streptomycin}(100 \mu \mathrm{g} / \mathrm{ml})$ 
(1:100; Sigma-Aldrich; Merck KGaA, Darmstadt, Germany) in an incubator with humidified atmosphere of $5 \% \mathrm{CO}_{2}$ at $37^{\circ} \mathrm{C}$.

Analysis of apoptosis. Apoptosis in the C6 rat glioma cell line was measured using the Annexin V-FITC Apoptosis Detection kit (BD Biosciences, San Jose, CA, USA). Following culture for $24 \mathrm{~h}$ the cells were seeded into 6 -well plates at a density of $3 \times 10^{6}$ cells/well and were treated with dimethyl sulfoxide (DMSO) alone as a control or with $5,10,15,20$ or $30 \mu \mathrm{M}$ dihydroartemisinin. Following incubation for $48 \mathrm{~h}$, the cells were washed two times with ice-cold PBS. The cells were then resuspended in $100 \mu \mathrm{l}$ binding buffer and incubated with $3 \mu \mathrm{l}$ Annexin V-fluorescein isothiocyanate (FITC; BD Biosciences) and $10 \mu \mathrm{l}$ propidium iodide (PI; BD Biosciences) at room temperature for $15 \mathrm{~min}$. The experiment was repeated three times.

Cell cycle analysis. C6 rat glioma cells were seeded at a density of $3 \times 10^{6}$ cells into each of the $10 \mathrm{~cm}$ culture dishes. The dishes contained complete RPMI-1640 medium (Gibco; Thermo Fisher Scientific, Inc.) and the cells were cultured for $24 \mathrm{~h}$. The cells were then treated DMSO as a control or with 10,20 or $30 \mu \mathrm{M}$ dihydroartemisinin for $48 \mathrm{~h}$. Following treatment, the cells were harvested, fixed in $70 \%$ ethanol at $-2^{\circ} \mathrm{C}$ for $24 \mathrm{~h}$ and washed with PBS. The cells were then subjected to staining with a 5\% PI solution according to manufacturer's instructions. Analysis of the cells was performed using a FACSCalibur flow cytometer with Cell Quest software Pro (5.1 version; BD Biosciences, Franklin Lakes, NJ, USA). The ModFit LT software package (version 2.0; Verity Software House, Inc., Topsham, ME, USA) was used to analyze the data.

Analysis of the cyclic 3',5'-monophopshate (cAMP) level. C6 rat glioma cells at a density of $1 \times 10^{4}$ cells/well in 24-well plates, following treatment with $5,10,15,20$ and $30 \mu \mathrm{M}$ dihydroartemisinin for $48 \mathrm{~h}$, were washed with PBS. The cells were treated with a radioimmunoprecipitation lysis buffer and then subjected to centrifugation to collect the supernatant, which was treated with mixture of $0.1 \mathrm{~N} \mathrm{HCl}$ and Dulbecco's modified Eagle's medium/F12 (Biological Industries Israel Beit-Haemek Ltd., Beit Haemek, Israel). The $30 \mu 1$ supernatant samples were collected and the concentration of cAMP was determined using an immunoassay. The supernatant was treated with mouse monoclonal anti-cAMP primary antibody (cat. no. 250532, 1:100; BI Biotech India Pvt., Ltd., New Dehli, India) to analyze the expression level of cAMP as previously described (15). The secondary antibody used was NorthernLights ${ }^{\mathrm{TM}} 557$ conjugated anti-mouse immunoglobulin G (cat. no. NL007, 1:5,000; BI Biotech India Pvt., Ltd.).

Analysis of bromodeoxyuridine (BrdU) labeling. A total of $1 \times 10^{4}$ cells/well in 24-well plates, following treatment with dihydroartemisinin for $48 \mathrm{~h}$, were washed and then distributed onto cover slips in 24-well plates. The coverslips were treated with $0.5 \%$ alcoholic solution of $\mathrm{H}_{2} \mathrm{O}_{2}$ followed by treatment with $\mathrm{HCl}$. The coverslips were washed with PBS and then treated with rat anti-BrdU antibodies (cat. no. ab152095, 1:100; Abcam, Cambridge, UK) at room temperature overnight. The coverslips were washed again with PBS and then incubated with secondary antibodies $(1: 5,000)$ for $1 \mathrm{~h}$ at room temperature.

Scanning electron microscopy (SEM). The cells were distributed onto the microslides at a density of $2 \times 10^{6}$ cells/well in 24-well culture plates. The plates were supplemented with RPMI-1640 medium. The cells were treated with 5, 10, 15, 20 or $30 \mu \mathrm{M}$ dihydroartemisinin or with DMSO alone as a control for $48 \mathrm{~h}$. The cells were fixed with glutaraldehyde $(2.5 \%)$ in a sodium cacodylate buffer [0.1 M (pH 7.4)] for $1 \mathrm{~h}$ at $4^{\circ} \mathrm{C}$ and then for $72 \mathrm{~h}$. Then, cells were fixed with osmium tetraoxide for $1 \mathrm{~h}$ at $4^{\circ} \mathrm{C}$. Dehydration of the cells was performed by treatment with gradient acetone and then with amyl acetate. The slides were dried, coated with an alloy of gold and palladium and examined under scanning electron microscopy (magnification, x750; Jeol-JSM-5200).

Statistical analysis. The results are presented as the mean \pm standard error from three independent experiments. The data was analyzed using one-way analysis of variance with the Bonferroni post-test. $\mathrm{P}<0.05$ was considered to indicate a statistically significant difference.

\section{Results}

Inhibition of C6 glioma cell growth by treatment with dihydroartemisinin. The untreated control cultures of C6 glioma cells were demonstrated to be growing at an increased rate during the $48 \mathrm{~h}$ compared with the treated cells. However, incubation of C6 glioma cells with 15,20 or $30 \mu \mathrm{M}$ dihydroartemisinin for $48 \mathrm{~h}$ led to a significant reduction in the cell count (Fig. 1). The reduction in the cell count in cultures treated with $20 \mu \mathrm{M}$ concentration of dihydroartemisinin was demonstrated to be -0.8 -fold compared with the control cultures at $48 \mathrm{~h}$.

Suppression of BrdU-labeling index (LI) in C6 glioma cells by treatment with dihydroartemisinin. Incubation of C6 glioma cells with $10,15,20$ or $30 \mu \mathrm{M}$ dihydroartemisinin for $48 \mathrm{~h}$ led to a reduction in the BrdU-LI compared with the control cultures (Fig. 2). The BrdU-LI positive C6 glioma cell population was reduced to $37 \%$ in the cultures treated with $20 \mu \mathrm{M}$ dihydroartemisinin for $48 \mathrm{~h}$ compared with the control cultures. Reduction in the BrdU-LI indicated a decrease in the uptake of BrdU by C6 glioma cells.

cAMP level reduction by treatment with dihydroartemisinin in C6 glioma cells. In the control (treated with DMSO alone) C6 glioma cells, the level of cAMP was demonstrated to be increased compared with the cells treated with dihydroartemisinin. Incubation of the C6 glioma cells with dihydroartemisinin led to a concentration-dependent reduction in the level of cAMP after $48 \mathrm{~h}$ of treatment (Fig. 3). The level of cAMP was reduced significantly in C6 glioma cells on incubation with $20 \mu \mathrm{M}$ dihydroartemisinin for $48 \mathrm{~h}$ $(\mathrm{P}<0.01)$.

Apoptosis induction by treatment with dihydroartemisinin in C6 glioma cells. Incubation of C6 glioma cell cultures with a range of dihydroartemisinin concentrations for $48 \mathrm{~h}$ caused an 


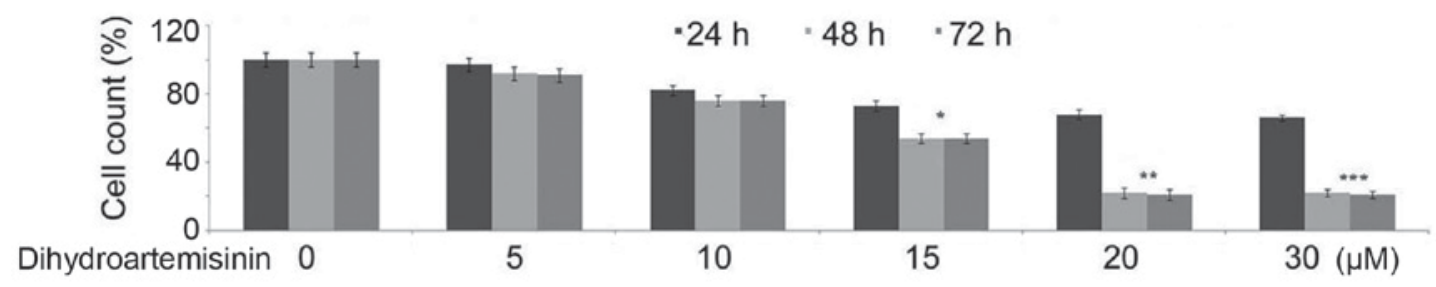

Figure 1. Inhibition of C6 glioma cell growth by dihydroartemisinin treatment. The cells were treated with $5,10,15,20$ or $30 \mu \mathrm{M}$ dihydro for 24,48 or $72 \mathrm{~h}$. The results are presented as the mean of three independent experiments. ${ }^{*} \mathrm{P}<0.05,{ }^{* *} \mathrm{P}<0.02$ and ${ }^{* * * *} \mathrm{P}<0.01$ vs. $0 \mu \mathrm{M}$.

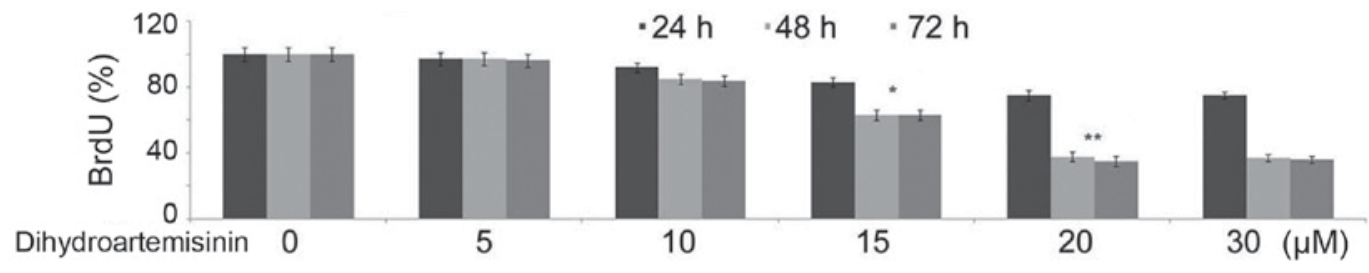

Figure 2. Reduction in the level of BrdU-LI in C6 glioma cells by treatment with dihydro. The cells were incubated with 5, 10, 15, 20 or 30 $\mu \mathrm{M}$ dihydroartemisinin for $48 \mathrm{~h}$ and then the level of BrdU-LI was analyzed. A dose dependent reduction was observed in the levels of BrdU-LI by treatment with dihydro after $48 \mathrm{~h}$. The results presented are the mean of three independent experiments performed in triplicate. ${ }^{*} \mathrm{P}<0.05$ and ${ }^{* *} \mathrm{P}<0.02$ vs. $0 \mu \mathrm{M}$. BrdU-LI, bromodeoxyuridine labeling index.

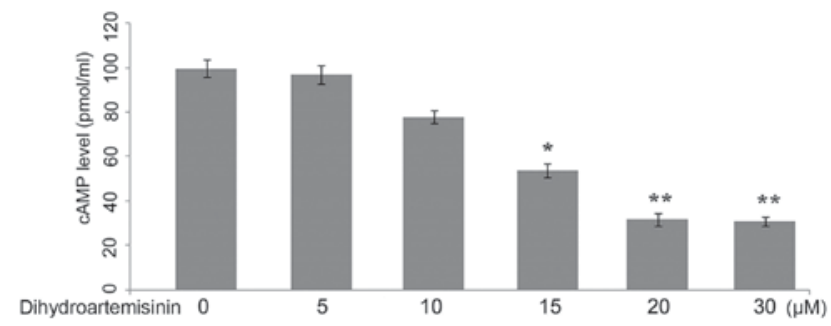

Figure 3. Inhibition of cAMP expression in C6 glioma cells treated with dihydro. The cells were incubated with $5,10,15,20$ or $30 \mu \mathrm{M}$ dihydroartemisinin for $48 \mathrm{~h}$ and the cAMP level was analyzed. The results presented are the mean of three experiments performed independently. ${ }^{*} \mathrm{P}<0.05$ and ${ }^{* *} \mathrm{P}<0.01$ vs. $0 \mu \mathrm{M}$. cAMP, cyclic 3',5'-adenosine monophosphate.

increase in the percentage of apoptotic cells compared with the control. The percentage of apoptotic cells in the cultures incubated with $20 \mu \mathrm{M}$ concentration of dihydroartemisinin was demonstrated to be $54.78 \%$ compared with $2.57 \%$ in the control cultures (Fig. 4). At 5, 10, 15, 20 or $30 \mu \mathrm{M}$ concentrations of dihydroartemisinin the population of apoptotic cells was demonstrated to be $6.23,11.34,33.97,54.78$ and $56.69 \%$, respectively.

Treatment with dihydroartemisinin causes cell cycle arrest at G0/G1 phase. Incubation of the C6 glioma cells with dihydroartemisinin for $48 \mathrm{~h}$ led to a significant reduction in the percentage of cells in $\mathrm{G} 2 / \mathrm{M}$ phase with an increase in cells in G0/G1 phase ( $\mathrm{P}<0.005$; Fig. 5). The population of cells in $\mathrm{G} 2 / \mathrm{M}$ phase at 10,20 and $30 \mu \mathrm{M}$ concentrations of dihydroartemisinin was demonstrated to be $45.43,34.67$ and $28.79 \%$, respectively compared with $47.67 \%$ in the control. Dihydroartemisinin at 10,20 and $30 \mu \mathrm{M}$ concentrations increased the G0/G1 phase cell population to $39.98,46.32$ and $51.65 \%$, respectively in comparison with $35.64 \%$ in the control. In $\mathrm{S}$ phase the cell population was demonstrated
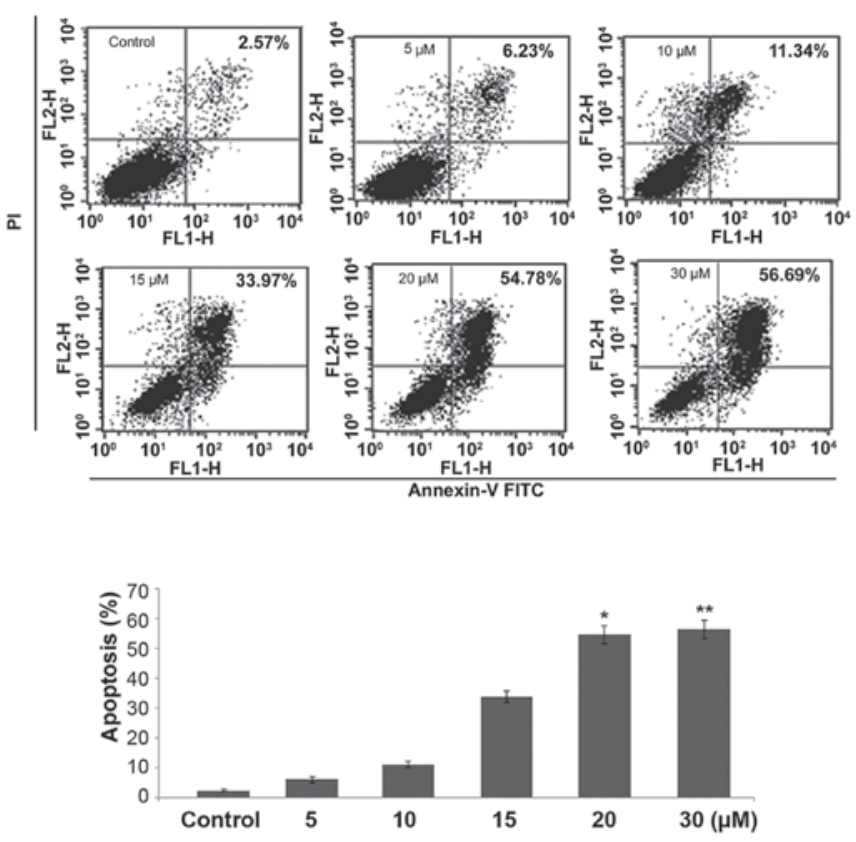

Figure 4. Effect of treatment with dihydroartemisinin on the induction of apoptosis in $\mathrm{C} 6$ glioma cells using flow cytometry. The cells were incubated with $5,10,15,20$ or $30 \mu \mathrm{M}$ dihydroartemisinin for $48 \mathrm{~h}$ and the percentage of apoptotic cells was analyzed. ${ }^{*} \mathrm{P}<0.05$ and ${ }^{* *} \mathrm{P}<0.001$ vs. control. PI, propidium iodide; FITC, fluorescein isothiocyanate.

to be $12.98,13.67$ and $14.59 \%$, respectively at 10,20 and $30 \mu \mathrm{M}$ dihydroartemisinin compared with $13.45 \%$ in the control (Fig. 5).

Assessment of cell morphology by SEM. The control cells exhibited a spindle-shaped morphology and were actively undergoing mitosis following $48 \mathrm{~h}$ of culture. The cells treated with dihydroartemisinin were round with small surface extensions (Fig. 6). 


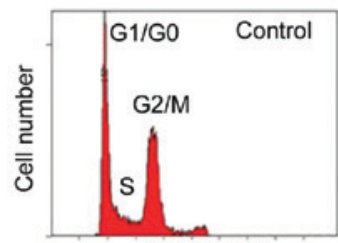

DNA content

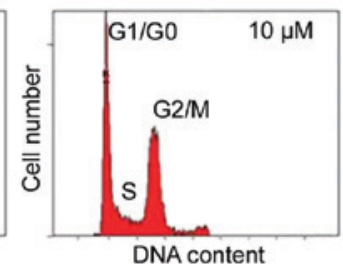

DNA content

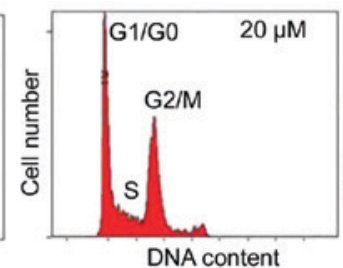

DNA content

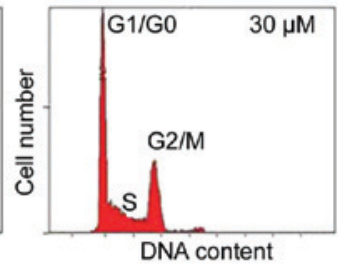

DNA content
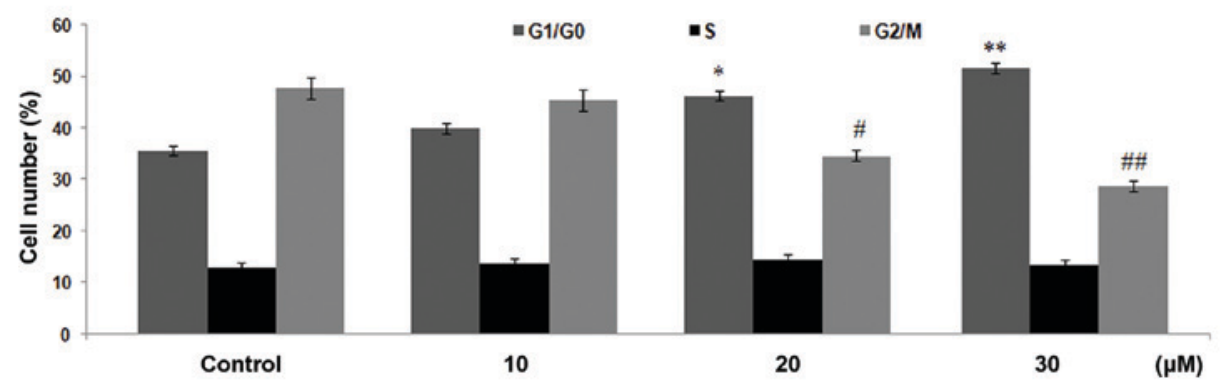

Figure 5. Effect of treatment with dihydroartemisinin on the cell cycle in C6 glioma cells. The alterations in the cell cycle in glioma cells was analyzed using flow cytometry. The cells were incubated with 10,20 or $30 \mu \mathrm{M}$ dihydroartemisinin for $48 \mathrm{~h}$ and the percentage of cells in each phase of the cell cycle was analyzed. ${ }^{*} \mathrm{P}<0.005$ and ${ }^{* *} \mathrm{P}<0.001$ vs. the control; ${ }^{\#} \mathrm{P}<0.001$ and ${ }^{\# \#} \mathrm{P}<0.002$ vs. the control.

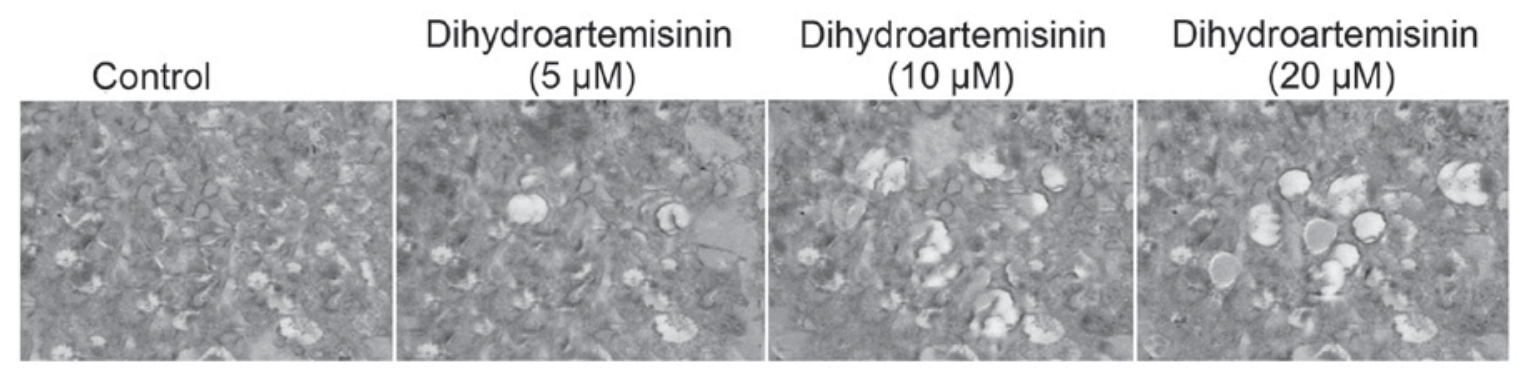

Figure 6. Effect of treatment with dihydroartemisinin on the morphology of glioma cells using a SEM. The cells were incubated with 5 , 10 or $20 \mu \mathrm{M}$ dihydro for $48 \mathrm{~h}$ and then analyzed using SEM (magnification, x750). SEM, scanning electron microscope.

\section{Discussion}

Efficient treatment of glioblastoma multiforme is a challenge for clinicians worldwide. Evaluation of natural products has led to the identification of a number of compounds, which exhibit an inhibitory effect on the growth of glioma cells (16-18). In the present study, the effect of dihydroartemisinin on C6 glioma cell proliferation was studied. The present study demonstrated that dihydroartemisinin treatment reduced the proliferation of C6 glioma cells, reduced the proportion of cells in S phase, reduced the level of cAMP and induced apoptosis.

The results of the present study demonstrated that dihydroartemisinin treatment inhibits the growth of C6 glioma cells with maximum inhibition $48 \mathrm{~h}$ following treatment. Analysis of the effect of dihydroartemisinin on the cell cycle revealed cells arrested in G0/G1 phase. Treatment of C6 glioma cells with dihydroartemisinin increased the percentage of cells in G0/G1 phase with a simultaneous decrease in cells in G2/M phase. Earlier studies have demonstrated that platelet-derived growth factor receptors (PDGFRs) cause an increase in the levels of cAMP on activation $(19,20)$. A higher rate of proliferation of C6 glioma cells has been demonstrated to be associated with PDGFs. cAMP is produced mainly in cellular mitochondria from ATP $(21,22)$. In glioma cells the presence of native $\beta$-adrenoreceptors (ADRs) and functional PDGFRs causes proliferation by increasing the level of cAMP $(19,20)$. The $\alpha$ and $\beta$-ADRs, which are coupled to G-proteins, lead to the accumulation of cAMP in the cells. In the present study, a reduction in the level of cAMP was demonstrated by dihydroartemisinin $48 \mathrm{~h}$ following treatment. Therefore, a reduction in the level of cAMP in C6 glioma cells following treatment with dihydroartemisinin may be the involved in the inhibition of cell growth. Inhibition of cell proliferation indicated that the effect of dihydroartemisinin on the induction of cell apoptosis should be examined further. The results from Annexin V-FITC/PI staining demonstrated an increase in the percentage of apoptotic cells following $48 \mathrm{~h}$ of incubation with dihydroartemisinin.

Alterations in the permeability of the mitochondrial membrane causes the release of cytochrome $\mathrm{c}$ and the activation of caspases, resulting in apoptosis (23-25). In the present study results from SEM demonstrated rounding of cells with the formation of small surface projections on treatment with dihydroartemisinin for $48 \mathrm{~h}$. In conclusion, treatment of the glioma cells with dihydroartemisinin exhibits antitumor effects by induction of apoptosis. Therefore, it may be valuable to evaluate dihydroartemisinin in animal models for the treatment of glioma. 


\section{References}

1. Curran WJ Jr, Scott CB, Horton J, Nelson JS, Weinstein AS Fischbach AJ, Chang CH, Rotman M, Asbell SO, Krisch RE, et al: Recursive partitioning analysis of prognostic factors in three Radiation Therapy Oncology Group malignant glioma trials. J Natl Cancer Inst 85: 704-710, 1993.

2. Maher EA, Furnari FB, Bachoo RM, Rowitch DH, Louis DN Cavenee WK and DePinho RA: Malignant glioma: Genetics and biology of a grave matter. Genes Dev 15: 1311-1333, 2001.

3. Chang SM, Lamborn KR, Malec M, Larson D, Wara W, Sneed P, Rabbitt J, Page M, Nicholas MK and Prados MD: Phase II study of temozolomide and thalidomide with radiation therapy for newly diagnosed glioblastoma multiforme. Int J Radiat Oncol Biol Phys 60: 353-357, 2004.

4. Fine HA, Wen PY, Maher EA, Viscosi E, Batchelor T, Lakhani N, Figg WD, Purow BW and Borkowf CB: Phase II trial of thalidomide and carmustine for patients with recurrent highgrade gliomas. J Clin Oncol 21: 2299-2304, 2003.

5. Marx GM, Pavlakis N, McCowatt S, Boyle FM, Levi JA, Bell DR, Cook R, Biggs M, Little N and Wheeler HR: Phase II study of thalidomide in the treatment of recurrent glioblastoma multiforme. J Neurooncol 54: 31-38, 2001.

6. Meshnick SR: Artemisinin: Mechanisms of action, resistance and toxicity. Int J Parasitol 32: 1655-1660, 2002.

7. O'Neill PM: Medicinal chemistry: A worthy adversary for malaria. Nature 430: 838-839, 2004.

8. Efferth T,Dunstan H, Sauerbrey A, Miyachi H and Chitambar CR: The anti-malarial artesunate is also active against cancer. Int J Oncol 18: 767-773, 2001.

9. Huang XJ, Ma ZQ, Zhang WP, Lu YB and Wei EQ: Dihydroartemisinin exerts cytotoxic effects and inhibits hypoxia inducible factor-1alpha activation in C6 glioma cells. J Pharm Pharmacol 59: 849-856, 2007.

10. Nam W, Tak J, Ryu JK, Jung M, Yook JI, Kim HJ and Cha IH: Effects of artemisinin and its derivatives on growth inhibition and apoptosis of oral cancer cells. Head Neck 29: 335-340, 2007.

11. Singh NP and Lai H: Selective toxicity of dihydroartemisinin and holotransferrin toward human breast cancer cells. Life Sci 70: 49-56, 2001.

12. Chen T, Li M, Zhang R and Wang H: Dihydroartemisinin induces apoptosis and sensitizes human ovarian cancer cells to carboplatin therapy. J Cell Mol Med 13: 1358-1370, 2009.

13. O'Reilly T, Wartmann M, Maira SM, Hattenberger M, Vaxelaire J, Muller M, Ferretti S, Buchdunger E, Altmann KH and McSheehy PM: Patupilone (epothilone B, EPO906) and imatinib (STI571, Glivec) in combination display enhanced antitumour activity in vivo against experimental rat C6 glioma. Cancer Chemother Pharmacol 55: 307-317, 2005.
14. Lokker NA, Sullivan CM, Hollenbach SJ, Israel MA and Giese NA: Platelet-derived growth factor (PDGF) autocrine signaling regulates survival and mitogenic pathways in glioblastoma cells: Evidence that the novel PDGF-C and PDGF-D ligands may play a role in the development of brain tumors. Cancer Res 62: 3729-3735, 2002.

15. Kaygisiz Z, Erkasap N, Yazihan N, Sayar K, Ataoglu H, Uyar R and Ikizler M: Erythropoietin changes contractility, cAMP, and nitrite levels of isolated rat hearts. J Physiol Sci 56: 247-251, 2006.

16. Buchdunger E, Cioffi CL, Law N, Stover D, Ohno-Jones S, Druker BJ and Lydon NB: Abl protein-tyrosine kinase inhibitor STI571 inhibits in vitro signal transduction mediated by c-kit and platelet-derived growth factor receptors. J Pharmacol Exp Ther 295: 139-145, 2000.

17. Yu C, Krystal G, Dent P and Grant S: Flavopiridol potentiates STI571-induced mitochondrial damage and apoptosis in BCR-ABL-positive human leukemia cells. Clin Cancer Res 8: 2976-2984, 2002.

18. Uziel O, Fenig E, Nordenberg J, Beery E, Reshef H, Sandbank J, Birenbaum M, Bakhanashvili M, Yerushalmi R, Luria D and Lahav M: Imatinib mesylate (Gleevec) downregulates telomerase activity and inhibits proliferation in telomerase-expressing cell lines. Br J Cancer 92: 1881-1891, 2005.

19. Sokołowska P and Nowak JZ: Constitutive activity of beta-adrenergic receptors in C6 glioma cells. Pharmacol Rep 57: 659-663, 2005.

20. Grobben B, De Deyn PP and Slegers H: Rat C6 glioma as experimental model system for the study of glioblastoma growth and invasion. Cell Tissue Res 310: 257-270, 2002.

21. Jaiswal BS and Conti M: Calcium regulation of the soluble adenylyl cyclase expressed in mammalian spermatozoa. Proc Natl Acad Sci USA 100: 10676-10681, 2003.

22. Baillie GS and Houslay MD: Arrestin times for compartmentalised cAMP signalling and phosphodiesterase-4 enzymes. Curr Opin Cell Biol 17: 129-134, 2005.

23. Adams JM and Cory S: The Bcl-2 protein family: Arbiters of cell survival. Science 281: 1322-1326, 1998.

24. Antonsson B and Martinou JC: The Bcl-2 protein family. Exp Cell Res 256: 50-57, 2000.

25. Salvesen GS and Dixit VM: Caspases: Intracellular signaling by proteolysis. Cell 91: 443-446, 1997. 